\title{
Oral Submucous Fibrosis - A Condition with Increasing Potential for Malignancy
}

Laxmidevi B. Lankesh ${ }^{1}$, Praveen $\mathrm{K} \mathrm{S}^{2}$

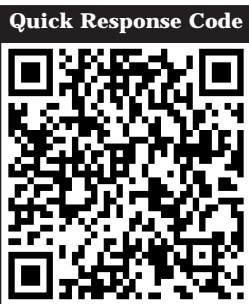

doi : $10.5866 / 2014.621563$

${ }^{1}$ Reader

2Senior Lecturer

Department of Oral Pathology and Microbiology

Sri Siddhartha Dental College and Hospital

B.H.Road, Agalakote,

Tumkur, Karnataka, India.

\section{Article Info:}

Received: J anuary 8, 2014

Review Completed: February 9, 2014

Accepted: March 8, 2014

Available Online: J uly, 2014 (www.nacd.in)

(c) NAD, 2014 - All rights reserved

Email for correspondence:

drlaxmi_op80@rediffmail.com

\begin{abstract}
:
Oral sumucous fibrosis was first described in the early 1950 s as a potentially malignant disorder predominantly seen in the people of Asian descent. The hall mark of the disease is submucosal fibrosis that affects most of the parts of oral cavity including the pharynx and esophagus. Even though the etiology of OSMF is multifactorial, areca nut is considered the prime causative factor. Areca nut is available in the market as freeze dried product in the form of pan masala, gutkha and mawa, in which it is in high concentration per chew and appears to cause OSMF rapidly, compared self-prepared conventional betel quid. In current days predominantly younger generation of the age group 20-30 years are affected, mainly because of the development of habit of chewing gutkha early in life as it is easily available in the market in attractive pouches at affordable price. The main gl obal concern regarding OSMF is the onset of slowly growing squamous cell carcinoma that has gradually increased the percentage of malignant transformation of OSMF in recent days. Here we report one such case of OSMF with developed squamous cell carcinoma in the retromolar area. Reporting of this may add one more case of malignant transformation of OSMF in the literature.
\end{abstract}

Key words: OSMF, malignant potential, squamous cell carcinoma, chewing habits, areca nut.

\section{Introduction}

OSMF (Oral Submucous Fibrosis), a distressing disease of oral cavity, was described in early 1952 by Schwartz who described it in five indian women from Kenya which he called "atrophica idiopathica mucosa oris", whereas the term oral submucosal fibrosis was given by J oshi in $1953 .{ }^{1}$ Although cases have been reported worldwide the prevalence is more in India, especially in southern parts. ${ }^{2}$

Although several etiological factors have been discussed in the literature, extensive investigation was done on areca nut. Carcinogens have been 
identified in the areca nut which is first clue for the slow growing of squamous cell carcinoma in those who use it chronically. ${ }^{3}$ First recorded malignant transformation was by Paymester in his one third of patient in Bombay. Later it was even elicited by Murthi et.al. According to them rate of malignant transformation is aroung $7-13 \% .{ }^{1}$ Restricted mouth opening in OSMF leads to morbitity and the malignant transformation increases the mortality.

Here we report a case of OSMF in a male patient who developed the squamous cell carcinoma in the retromolar area when he reported to the hospital. The patient had a positive history of chewing gutkha since 20 years, around 10 packets per day.

\section{Case report:}

A 34yr old male patient reported to the department of oral medicine complaining of restricted mouth opening and bleeding gums. He gave a history of chewing pan, tobacco, gutkha since 20years, around 10 packets of gutkha per day.

Extra-oral examination revealed restricted mouth opening with inter-incisal opening of about $15 \mathrm{~mm}$ (Figure 1). On palpation fibrous bands were felt in both right and left cheeks. Diffuse proliferative growth on the right retromolar region was seen intra-orally with blanching of the oral mucosa. Biopsy was taken from right bucal mucosa and retromolar area and was sent to histopathological examination. Laboratory blood investigations were noncontributory

Tissue from buccal mucosa showed stratified squamous orthokeratinized epithelium with loss of rete pegs. J uxta epithelial connective tissue showed thick bundles of mature collagen fibrers with scattered fibroblasts. Moderate infiltration of chronic inflammatory cells was seen throughout the connective tissue with deeper areas showing degeneration of muscle fibre bundles (Figure 2). All features were suggestive of OSMF.

Tissue from retromolar area showed presence of stratified squamous parakeratinised epithelium with invasion in to the underlying connective tissue. The epithelial cells are seen in the form of cords or groups with one area showing formation of keratin pearls with in the connective tissue (Figure 3), suggesting the development of Squamous Cell Carcinoma from the retromolar area. Therefore the OSM F with development of OSCC from retromolar area was confirmed by the biopsy report.

\section{Discussion}

Oral submucous fibrosis is a chronic disease of oral mucosa characterized by inflammation and progressive fibrosis of lamina propria and deeper connective tissue, followed by stiffening of an otherwise yielding mucosa resulting in difficulty in opening the mouth. ${ }^{4}$ OSMF a precancerous condition as we know, can progress to OSCC, and approximately $30 \%$ of oral cancers in India are attributable to areca nut/gutkha chewing. ${ }^{5}$

Epidemiological and in vitro experimental studies have shown that chewing areca nut is the major etiological factor for OSMF. However there is regional variation in the type of areca nut products used in India. The betel quid was most popular and widely practiced habit in elderly people especially villagers, hence the risk were focused in these groups. But when the Indian market was introduced with the commercially available areca nut products such as pan masala and gutkha, the relative frequency was shifted from elder to younger generation as the habit was more easily cultivated by the latter group and the affordability of the product. 3,6

Gutka is a powdered or granulated mixture containing a variety of ingredients, including tobacco, areca nut, limes, catechu, and spices packed in tins and handy foil sachets. Chewing gutkha has been shown to have carcinogenic, genotoxic and clastogenic effects. ${ }^{5}$ Alkaloids present in the areca nut, assessed biochemically include arecoline, arecaidine, guvacine and guvacoline, of which arecoline is the main agent (Flowchart 1$){ }^{7}$

Further it has been suggested that atrophy of epithelium in OSMF is possibly more susceptible to carcinogens produced by areca nut. A probable prerequisite for cancer development is the action of carcinogens that starts as intercellular edema and later epithelial atypia which is the first evidence for the progression of oral squamous cell carcinoma (Flowchart 2). Thus in the Plummer-Vinson syndrome, a strong tendency for cancer devel opment 


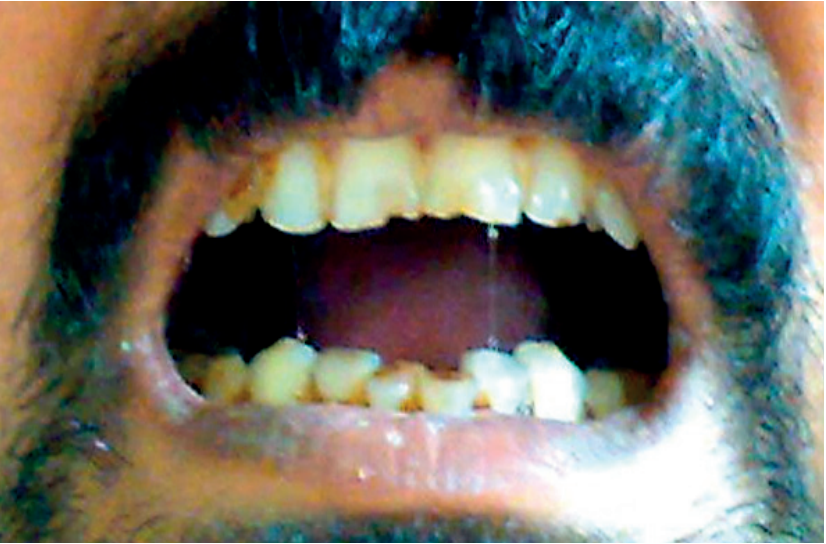

Figure 1: Extra oral photograph showing restricted mouth opening of the patient.

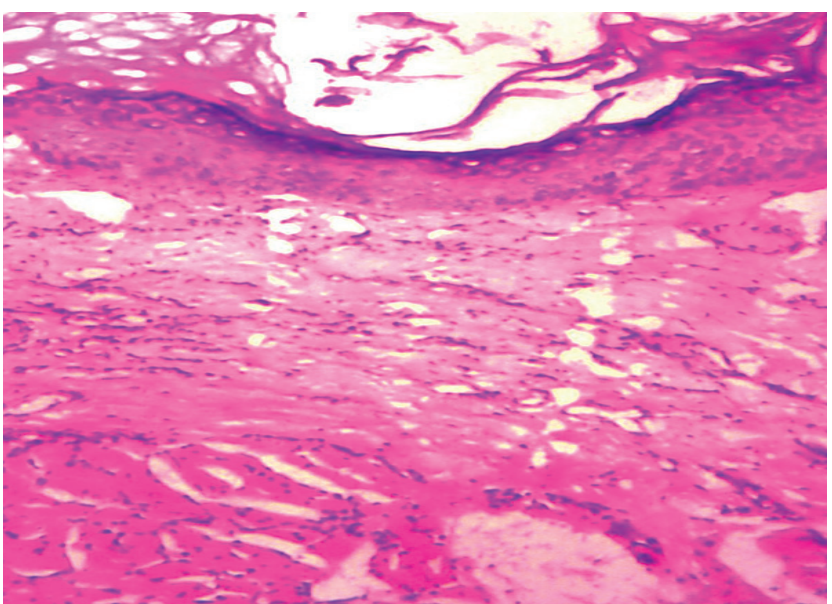

Figure 2: Section showing dense fibrosis of the collagen fibers in the connective tissue with overlying atrophic stratified squamous parakeratinised epithelium (H\& E 100X).

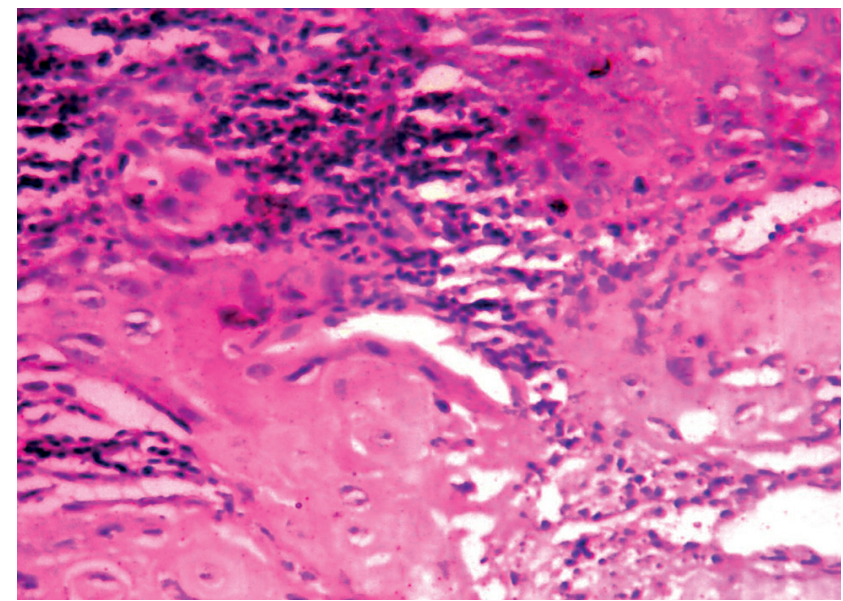

Figure 3: Squamous cell carcinoma: Section showing the islands of epithelial cells with keratin pearl formation in the connective tissue (H\&E 100X)

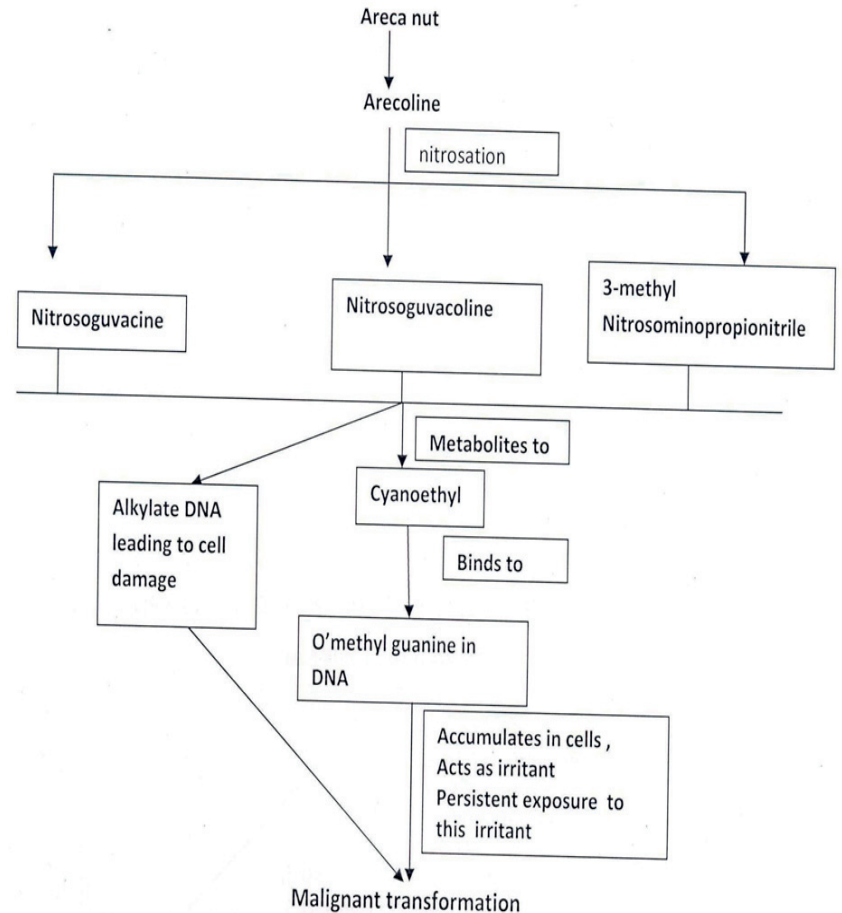

Flowchart 1: Depecting the Areca Nut metabolism in the oral cavity

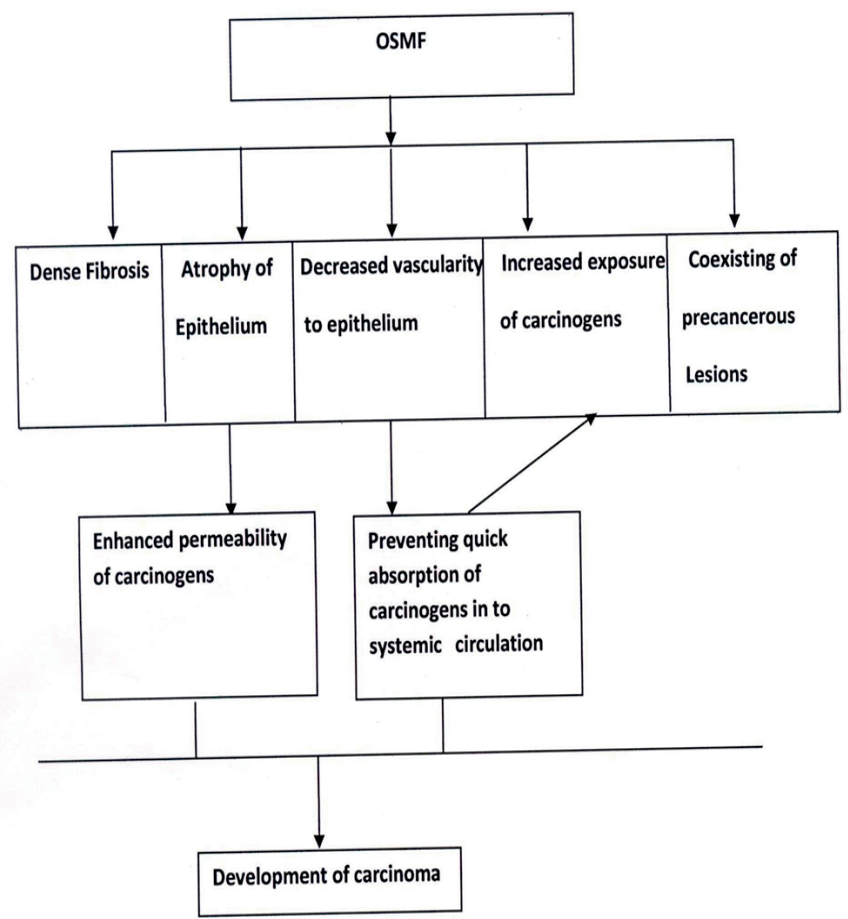

Flowchart 2: Possible mechanism of malignant transformation of OSMF 
is found in the atrophic mucosa of the digestivetract. Submucous fibrosis starts primarily in the juxtaepithelial connective tissue; however the damage to the epithelium is the sequel of the changed connective tissue. Interpapillary epithelium is thinner, would potentially allow hazardous chemical substance of arecanut extracts to permeate through this narrow epithelial strips in to the connective tissue resulting in the accumulation of neutrophils via chemotactic mechanism and persistence inflammation. ${ }^{8}$

The precancer ous nature of the OSMF was first described by Paymaster in 1956 when he observed slow growing squamous cell carcinoma in one third of the patients with the disease at Tata Memorial Hospital in Bombay. ${ }^{8}$ This was confirmed by various groups and Pindborg in 1972 who put forward the five criteria's to prove the disease is precancerous. Among the 100 patients of OSCC, 40 showed OSMF in the study group of Pindborg. Epithelial atypia was seen in $11.5 \%$ in areas of oral submucous fibrosis remote from the cancer where as in the biopsies taken in the vicinity of Cancer of OSMF, epithelial atypia was seen in $71.4 \% .{ }^{9}$ According to long follow up study, a transformation rate of $7.6 \%$ over a period of 17 years was reported. ${ }^{10} \mathrm{Hospital}$ based study conducted by Hazarey et.al showed the malignant rate was around $33 \% .^{6}$ These studies reveal a gradual increase in the percentage of malignant transformation.

Hence the relative risk of developing cancer is around $5.98 \%$ for the chewers. ${ }^{4}$ Thus the habit of chewing Gutkha has not only given rise to increased prevalence of OSMF in younger generation but also increased incidence of oral cancer in the same group, shifting the incidence rate of oral cancer from adult age group to younger, which is a global concern.
This article presents one such case and emphasizes the global health concern regarding the younger generation who are addicted to the chewing habits of areca nut, that not only decreasing their quality of health but also decreasing the life span. Awareness regarding the OSMF transformation to OSCC may stringently require to all the younger generation from oral health professionals.

\section{References}

1. Rajendran R. Oral submucous fibrosis: etiology, pathogenesis, and future research. Bulletin of the World Health Organization 1994, 72 (6): 985-996

2. PindborgJ .J , Mehta F. S, Gupta P.C, Daftar D.K. Prevalence of oral submucous fibrosis among 50,915 indian villagers. Br J Cancer 1968; 22(4): 646-654

3. Angadi P.V, Krishnapillai R. Evaluation of PTEN Immunoexpression in Oral Submucous Fibrosis: Role in Pathogenesis and Malignant Transformation. Head and Neck Pathol 2012; 6:314-321.

4. Garg K N, Raj V, Shaleen Chandra. Trends in frequency and duration of tobacco habit in relation to potentially malignant lesion: A 3 years retrospective study. J Oral Maxillofac Path 2013; 17(2): 201-6.

5. Nair U, Bartsch $\mathrm{H}, \mathrm{Nai} J$. Alert for an epidemic of oral cancer due to use of the betel quid substitutes gutkha and pan masala: a review of agents and causative mechanisms. Mutagenesis 2004; 19(4 ):251-262.

6. V.K.Hazarey, D.M.Erlewad, K.A.Mundhe, andS.N.Ughade. Oral submucous fibrosis: study of 1000 cases from central India. J Oral Path Med 2007; 36(1):12-17.

7. Ghom A, Mhaske S. Premalignant lesions and conditions (Chapter 12) In: Textbook of oral pathology. $2^{\text {nd }} \mathrm{Edn}$, J aypee Brothers Medical Publishers (P) Ltd, New Delhi, 2013; pg. $219-250$

8. Pindborg J J . Oral Submucous Fibrosis as a Precancerous Condition. J Dent Res 1966; 45:546.

9. Pindborg, J . J , Zachariah, J . F requency of Oral Submucous Fibrosis among 100 Indians with Oral Cancer. Bull WHO 1965; 32:750-753.

10. Murti PR, Bhonsle RB, Gupta PC, Daftary DK, Pindborg JJ, Mehta FS. Etiology of oral submucous fibrosis with special Reference to the role of areca nut chewing. J Oral Pathol Med 1995; 24: 145-152.

\section{Gain quick access to our journal online View our journal at www.nacd.in}

